\title{
Basin Structure Effects in the Kobe Area Inferred from the Modeling of Ground Motions from Two Aftershocks of the January 17, 1995, Hyogo-ken Nanbu Earthquake
}

\author{
Arben Pitarka, ${ }^{1, *}$ Kojiro Irikura, ${ }^{1}$ Tomotaka Iwata, ${ }^{1}$ and Takao Kagawa ${ }^{2}$ \\ ${ }^{1}$ Disaster Prevention Research Institute, Kyoto University, Uji 611, Japan \\ ${ }^{2}$ Geo-Research Institute, Osaka Soil Test Laboratory, Osaka 550, Japan
}

\begin{abstract}
Ground motion records from aftershocks of the January 17, 1995, Hyogo-ken Nanbu earthquake provide a good opportunity for evaluating the Osaka basin edge effects on wave propagation in the Kobe area. Aftershock ground motion recorded in a small array deployed at sites within and outside the heavily damaged zone, east of Kobe City, show very large amplification at the sedimentary sites located close to the basin edge. The peak velocities at sediment sites were up to 15 times larger than those at the rock site. To model the effect of the basin edge structure and the source radiation in the frequency range $0.1-2.5 \mathrm{~Hz}$, we calculate double-couple point source SH seismograms using two-dimensional finite difference techniques. By comparing the synthetic seismograms with the transverse component of the observed waveforms from two selected aftershocks, we find that the northern edge of the Osaka basin has a fault-like structure, dipping north. The rather complex basin edge structure causes seismic energy to focus at sites close to the edge. The constructive interference of different basin generated waves amplifies the ground motion. The focal area and the amplification due to the basin structure depend on the source location, i.e. the arrival direction of seismic waves. Our results indicate that the basin edge effect is one of the reasons why the zone heavily damaged during the main shock lies along a narrow belt. They also indicate that the thin surface sediments in the Kobe region amplify the ground motion at frequencies around $2 \mathrm{~Hz}$ considerably.
\end{abstract}

\section{Introduction}

There is an increasing concern about the seismic energy focussing effects due to basin edge structures on the amplification of ground motions at sites within a basin, during nearfield events (Aki, 1988; Hauksson, 1990; Frankel, 1993; Scrivner and Helmberger, 1994; Gao et al., 1996). The most recent earthquakes that have demonstrated this phenomena are the January 17, 1994 Northridge, California, and January 17, 1995 Hyogo-ken Nanbu, Japan, earthquakes.

The ground motion amplification pattern observed during aftershocks of the Northridge earthquake shows significant amplification at sites located close to the southern edge of the San Fernando Valley and northern edge of the Los Angeles basin. Without excluding the surface sediment effect, such observation was explained mostly by basin structure effects (Gao et al., 1996). Using two- dimensional wave propagation modeling for the Los Angeles basin, Graves (1995) and Pitarka and Irikura (1996) found that strong lateral heterogeneities in the surface sediments, which can be considered as shallow micro-basin structures, and basin edge effects were responsible for the large amplitude of the later phases arriving after the direct S-waves observed during the main shock at sites close to northern edge of the Los Angeles basin.

Ground motion records from the January 17 , Hyogo-ken Nanbu earthquake show a large variation in amplitude and waveforms even within small areas along the northern edge of the Osaka basin (Toki et al., 1995). This earthquake was generated by a basin-bounding fault. One of the most striking particularities of this earthquake is the damage distribution along a very narrow belt in Kobe City. It would therefore be interesting to know how the basin structure in Kobe area affected ground motion, and to what extent it was responsible for the spatial

Received July 7, 1995; Accepted January 5, 1996

* To whom correspondence should be addressed at the present address: Woodward Clyde Consultants, CA, 91101 , U.S.A. 
distribution of the damage zone during the January 17 earthquake. By modeling wave propagation in a three-dimensional circular sedimentary basin due to a point source, Shinozaki and Yoshida (1995) explained the spatial distribution of the damage as seismic energy focussing at sites close to the basin edge. Strong ground motion simulation from the main shock, in Chuo ward, Kobe City (Kawase and Hayashi, 1995) and an analytical study of ground motion amplification in Kobe City, based on planar shear-wave propagation in the sedimentary basin (Motosaka and Nagano, 1995), suggest that both a deep basin structure and shallow sedimentary layers have to be taken into account to explain the damage concentration in Kobe. An aftershock observation in the western segment of the damage zone shows significant amplification at sediment sites as compared to rock sites (Kudo et al., 1995). However, the differences in ground motion between hard soil and soft soil sites were not large, even though the damage ratio was significantly different there.

The near-field ground motions from the main shock were mainly affected by the complex source process (Sekiguchi et al., 1996; Pitarka et al., 1995; Kamae and Irikura, 1995). Therefore separation of the basin structure effects from the source effects is very difficult to perform.

In this study, we investigate the effect of the basin edge geometry on the amplitudes and waveforms of ground motions from aftershocks, observed in a small array deployed at sites within and outside the heavily damaged zone in Higashinada, east of Kobe City. We calculate SH seismograms using a twodimensional finite difference method to model the effects of the basin structure and source radiation in the frequency range of $0.1-2.5 \mathrm{~Hz}$. By comparing the synthetic and observed seismograms of ground motions from two aftershocks that are suitable to be modeled by the above-mentioned method, we discuss the relation between the structural complexities of the basin's northern edge and their effects on the spatial distribution of ground motion amplification.

\section{Array Observation and Ground Motion Data Analysis}

In this section, we analyze the ground motions from seven aftershocks recorded at a small aperture array installed by a group of organizations (Iwata et al., 1995). The array is located in Higashinada ward, across the damaged zone of the January 17. Hyogo-ken Nanbu earthquake. An emphasis is placed on finding evidences of basin structure effects.

Table 1 lists the aftershock locations and magnitudes (hereafter the aftershocks will be identified by their index number shown in Table 1), and Fig. 1 shows the distribution and the location of a station in the array (KMC) installed on rock. Five of the considered aftershocks are almost aligned along a line, nearly vertical to the basin edge and having an azimuth of $25^{\circ}$ from the observation array. Their epicentral distances from the basin edge range from $1.0-8.0 \mathrm{~km}$.

The station array location, together with the heavily damaged zone, shown in Fig. 2.

Table 2 lists station abbreviations, locations and site specifications. KMC is located on rock, close to the northern edge of the Osaka basin, while $\mathrm{KOB}$, FKI, ASY are on alluvium sites and FKE is on a reclaimed site. At the stations, velocity-type seismometers $(0.02-30 \mathrm{~Hz})$ with high dynamic range (Iwata et al., 1995) are installed.

Figure 3 shows the unfiltered velocity data from the seven aftershocks. The seismograms are lined up

Table 1. Aftershock location.

\begin{tabular}{|c|c|c|c|c|c|c|c|c|c|}
\hline \multirow{2}{*}{ No. } & \multicolumn{5}{|c|}{ Date } & \multirow{2}{*}{$\begin{array}{c}\text { Lat. (N) } \\
\text { (deg.) }\end{array}$} & \multirow{2}{*}{$\begin{array}{l}\text { Long. (E) } \\
\text { (deg.) }\end{array}$} & \multirow{2}{*}{$\begin{array}{l}\text { Dep. } \\
(\mathrm{km})\end{array}$} & \multirow{2}{*}{$M_{\mathrm{JMA}}$} \\
\hline & $\mathrm{M}$ & $\mathrm{D}$ & $\mathrm{H}$ & $\mathrm{M}$ & $S$ & & & & \\
\hline 1 & 1 & 23 & 21 & 44 & 11.80 & 34.79 & 135.32 & 16 & 4.3 \\
\hline 2 & 1 & 25 & 23 & 15 & 57.16 & 34.78 & 135.31 & 16 & 4.7 \\
\hline 3 & 1 & 26 & 1 & 1 & 18.38 & 34.77 & 135.27 & 12 & 3.5 \\
\hline 4 & 1 & 31 & 8 & 24 & 18.07 & 34.74 & 135.29 & 4 & 3.2 \\
\hline 5 & 1 & 29 & 0 & 27 & 12.51 & 34.74 & 135.28 & 4 & 2.9 \\
\hline 6 & 2 & 2 & 16 & 19 & 27.71 & 34.69 & 135.15 & 17 & 4.2 \\
\hline 7 & 2 & 3 & 20 & 36 & 55.31 & 34.73 & 135.26 & 11 & 3.4 \\
\hline
\end{tabular}




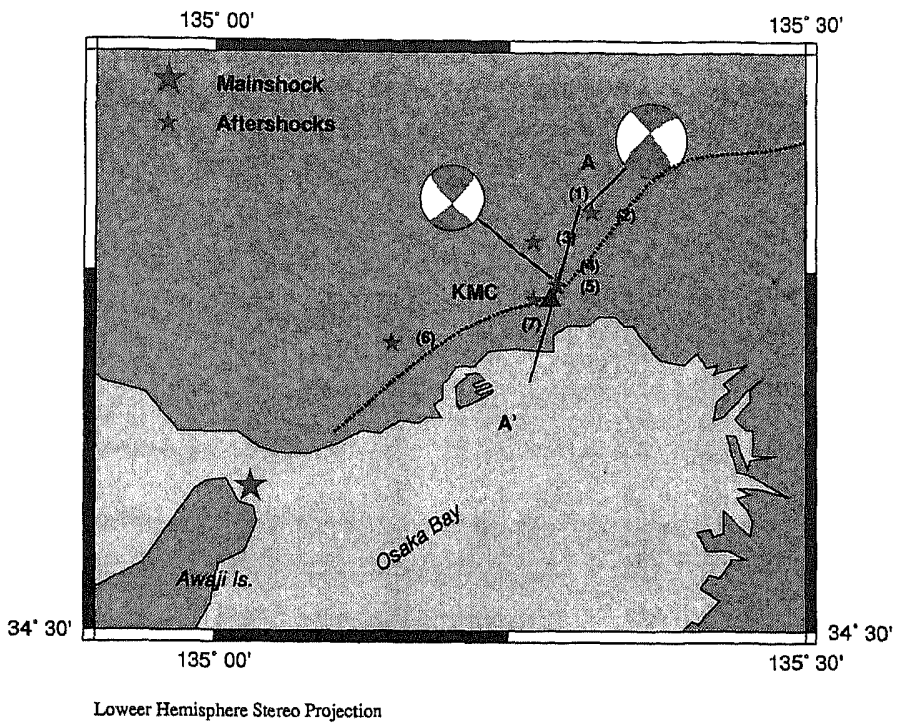

Fig. 1. Map of the Osaka basin area showing the aftershock location (star), rock-site station KMC (filled triangle) and the northern basin boundary (dotted line). The numbers next to the stars correspond to the aftershock number listed in Table 1. The locations of the two aftershocks (open stars) and their focal mechanisms used in the simulations are also shown. The two-dimensional velocity models used in this study correspond to the cross-section along line $\mathrm{A}-\mathrm{A}^{\prime}$.

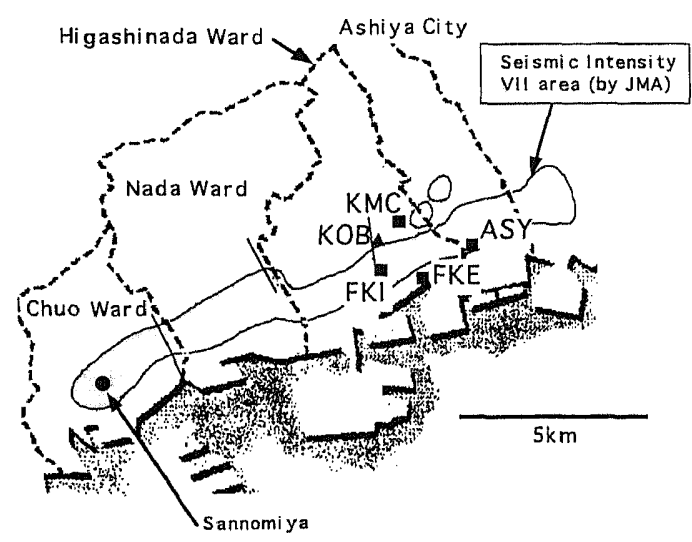

Fig. 2. Locations of array observation stations in Higashinada ward, Kobe City. Shaded area represents the heavily damaged zone and the solid lines the seismic profiles utilized to construct a velocity model.

by the direct S-wave arrival on the E-W component at KMC. Figure 4 shows the peak velocity amplitude ratio between the sediment sites and the rock site calculated from band-pass filtered data $(0.1-3.0 \mathrm{~Hz})$. Aftershock No. 3, which was not recorded at all of the sites, is excluded from this figure.
Depending on the aftershock location, there are visible differences in the waveforms and remarkable differences in the peak amplitude amplification from site to site. In general, for all of the aftershocks, the amplifications are largest at FKI. The largest amplification is observed during aftershock No. 2 , located north of the array. For this aftershock, the peak velocity amplitude ratio between FKI and $\mathrm{KMC}$, calculated from the filtered data, is a factor of 15 and 14 in the N-S and E-W components, respectively.

There is a considerable change in amplification depending on the aftershock location, too. The incidence angle of the direct $\mathrm{S}$-waves at the sedimentary sites (KOB, FKI, and FKE) varies within a narrow range of $45^{\circ}$ from aftershock to aftershock. Therefore, the source location-dependent amplification, observed at the sedimentary sites at frequencies $0.1-3.0 \mathrm{~Hz}$, cannot be simply explained by changes in the seismic response of the surface sedimentary layers, due to the difference in the incidence angle of the direct S-waves. As it will be shown in an other section, the basin structure and wave path affect ground motion at those sites considerably.

In the scope of evaluating the basin edge effects, 
Table 2. List of array observation stations in Higashinada ward, Kobe City.

\begin{tabular}{|c|c|c|c|c|c|c|c|}
\hline \multirow{2}{*}{$\begin{array}{l}\text { Station } \\
\text { code }\end{array}$} & \multicolumn{3}{|c|}{ Lat.(N) } & \multicolumn{3}{|c|}{ Long. (N) } & \multirow{2}{*}{ Site conditions } \\
\hline & (deg.) & $(\min )$ & (s) & (deg.) & $(\min )$ & $(\mathrm{s})$ & \\
\hline $\mathrm{KMC}$ & 34 & 43 & 47.0 & 135 & 17 & 10.8 & Sandstone \\
\hline $\mathrm{KOB}$ & 34 & 43 & 30.0 & 135 & 16 & 51.6 & Alluvium \\
\hline FKE & 34 & 42 & 58.7 & 135 & 17 & 36.9 & Sand bank \\
\hline FKI & 34 & 43 & 05.2 & 135 & 16 & 53.1 & Alluvium \\
\hline ASY & 34 & 43 & 27.4 & 135 & 18 & 30.6 & Alluvium \\
\hline
\end{tabular}



Fig. 3. Observed ground velocities at array stations. The seismograms are lined up by the direct S-wave arrival on the E-W component at KMC. Numbers to the right of the seismograms are peak velocities in $\mathrm{cm} / \mathrm{s}$ and those to the left are the aftershock identification numbers shown in Table 1.

it is particularly interesting to analyze and compare the ground motion records at $\mathrm{KOB}$ and $\mathrm{KMC}$. KOB is located very close to $\mathrm{KMC}$, a few hundred meters away from the basin edge, on relatively hard sediments. For aftershocks located to the north of the array, the radiation pattern effect is the same at both of these stations because they have almost the same azimuth. Therefore, for these aftershocks, the relative difference in amplitudes and waveforms can be attributed mainly to the local site and basin edge effects.
The waveforms at $\mathrm{KOB}$ are different from those at KMC (see Fig. 3). The first pulse, related with the first direct S-wave, is followed by several later pulses. In the case of aftershocks located north of the site, independently from the epicentral distance, the peak amplitudes of the later phases are larger than that of the direct wave. They indicate a rather complicated basin edge geometry which causes the multipathing effect. The multipathing effect, due to the irregular interfaces between the basement and the sediments and between the basin sediment layers, 
(1)
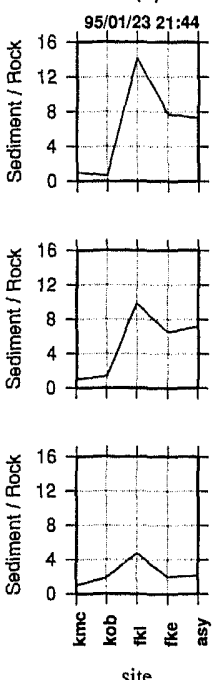

site
(2)
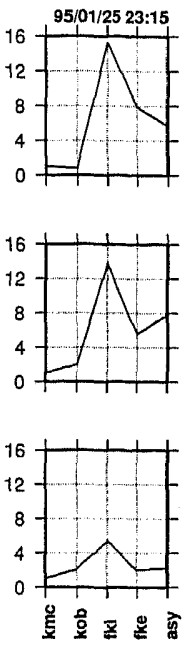

site

\section{VELOCITY PEAK AMPLITUDE RATIOS}

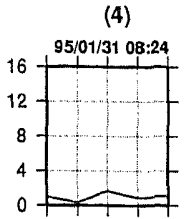

(5)


site

site

site

Fig. 4. Peak velocity amplitude ratio between the sediment sites and the rock site calculated from the band-pass filtered data $(0.1-3.0 \mathrm{~Hz})$. On top of each panel, the date of the aftershock and the corresponding number is shown.

can increase the peak amplitude of phases coming after the direct S-wave and extend the waveform coda (Scrivner and Helmberger, 1994). The coda waves are clear on the E-W component of the seismograms from aftershock Nos. 1, 2, 3, 5, and 6.

Unlike the aftershocks located north of the epicenter, in the case of aftershock Nos. 6 and 7, located to the west, there is a considerable difference in the arrival time of the direct $\mathrm{S}$-wave at $\mathrm{KOB}$ from that at KMC (see Fig. 3). This shows that waves generated by these two aftershocks propagate through different wave paths inside the basin. Moreover, they are considerably amplified. These observations indicate azimuthal-dependent basin effects at KOB caused by a complex basin edge structure.

In the following section, we evaluate the basin structure effect along the north-south direction by modeling the SH waves from aftershock Nos. 2 and 4 using two-dimensional velocity structures along a profile of the line $\mathrm{A}-\mathrm{A}^{\prime}$, passing through the aftershock epicenters and the array, as shown in Fig. 1.

\section{Waveform Modeling}

The two aftershocks discussed in this section are predominantly strike-slip $(\mathrm{H}$. Nemoto, personal communications); the main shock had similar focal mechanism. Their locations and focal mechanisms are shown in Fig. 1. The hypocenter of aftershock No. 2 is $7 \mathrm{~km}$ further from the edge of the Osaka basin and deeper than the hypocenter of aftershock No. 4 , which is only $1 \mathrm{~km}$ away. The difference in source location between these two events allows us to look at how the effect of basin edge geometry on waveforms changes as the seismic source is moved away from the basin edge.

To model the wave propagation in a heterogeneous two-dimensional structure, we use the finite difference method based on a second order of accuracy scheme (Boore, 1972). The synthetic velocity seismograms are generated by using the formulation described in Vidale et al. (1985). In this approach, the line source solution is mapped into the point-source solution by a simple transformation (Helmberger and Vidale, 1988). The advantage of this technique is that it can produce point-source synthetic waveforms with two-dimensional codes. The accuracy of the synthetic measurements is band-limited in the frequency domain. The numerical dispersion introduced by the finite-difference approximation affects high frequencies, while the asymptotic solution for doublecouple sources, which is used to produce the

Vol. 44, No. 5, 1996 
appropriate radiation pattern with two-dimensional codes, breaks down for long periods. The grid sizes used in the finite-difference calculation of the closest and farthest aftershocks were respectively 10 and $13 \mathrm{~m}$. The lowest shear-wave velocity in the models is $300 \mathrm{~m} / \mathrm{s}$. Consequently, we band-pass filtered both the synthetic and recorded waveforms at frequencies of $0.1-3.0 \mathrm{~Hz}$ in the case of the closest aftershock and $0.1-2.5 \mathrm{~Hz}$ in the case of the distant one. As it will be discussed in the following section, the basin edge effect is not very effective at higher frequencies.

Our approach to modeling the structure is to use a cross section along the line $\mathrm{A}-\mathrm{A}^{\prime}$ as a starting velocity model. The initial model is based on limited information such as seismic reflection profiles and geological structure (Hujita and Kazama, 1982), and corresponds to an average structure across an azimuth range of a few degrees around line $\mathrm{A}-\mathrm{A}^{\prime}$.

First, we analyze the factors controlling the waveform and amplitude at the sedimentary sites. Particular attention is placed to matching the waveform at KOB. The appropriateness of the model is tested by modeling the two aftershocks. Finally, we propose our preferred model, in which the synthetic waveforms match the data from both aftershocks better than other models.

The seismic moment used in the simulations is scaled by matching the peak amplitude at the rock site, KMC, even though the waveforms at this station are not simple. The direct S-wave is followed by later phases with comparable amplitude (see Fig. 3 , trace Nos. 2 and 4). It is probable that the later arrivals are waves scattered by a three-dimensional rock structure or the surface topography, or fracturated by multiple faults (Tessmer and Kosloff, 1994). The wave path seems to have smaller effects at frequencies higher than $1 \mathrm{~Hz}$ because the waveform from the distant aftershock, which is supposed to be affected by the wave path, is simpler than that from the closer one.

Considering the simple source process of such small aftershocks, the motion observed at the rock site (KMC) cannot be regarded as an incident wave into the basin. Being interested in explaining the relative changes of the amplification rate among sites inside the basin, we do not try to match the whole waveform observed at the rock site. We use a bell-shaped moment rate function that matches the first pulse of the direct S-wave and a simplified velocity structure outside the basin.

\section{Results}

Modeling is done only for the SH waves. The $\mathrm{P}-\mathrm{SV}$ waves are more complicated to treat because of the conversions between $P$ and $S$ energy at interfaces. They are more sensitive to changes in the model. Our knowledge on the Osaka basin edge structure is not sufficient to have confidence in modeling P-SV waves.

At each station, the synthetic waveform is compared with the transverse component of the ground motion obtained by rotating the original data.

The velocity model (Model-I), with a vertical basin edge, used as the starting model in our simulations, is shown in Fig. 5. We utilized shear-wave velocities of 1.0 and $0.5 \mathrm{~km} / \mathrm{s}$ respectively for the consolidated and shallow sediments (Kagawa et al., 1993). The synthetic seismograms calculated at equally-spaced receivers distributed on the surface crossing to the basin edge are shown in Fig. 6(a) and (b) respectively for aftershock Nos. 2 and 4. We used a bell-shaped source time function with a pulse duration of $0.5 \mathrm{~s}$ for both aftershocks.

The simulated velocity seismograms from the two aftershocks are very similar. The most prominent phases, seen at receivers inside the basin and affected by the geometry of the basin edge, are two S-wave arrivals originating from the direct $\mathrm{S}$-wave transmitted in the basin in two different directions, one from the lower boundary (hereafter called lowerboundary-transmitted-wave) and the other from the northern vertical boundary (hereafter called basinedge-transmitted-wave). The lower-boundary-transmitted-wave appears as the first phase at receivers located more than $700 \mathrm{~m}$ away from the basin boundary. At these receivers the amplitude of the basin-edge-transmitted-wave, which propagates longer in the soft sediments, depends on the source location. In the case of the closer source (aftershock No. 4), located only $1 \mathrm{~km}$ away from the basin edge at a depth of $3 \mathrm{~km}$, the transmission coefficient at the basin edge is relatively small. Consequently, the amplitude of the basin-edge-transmitted-wave is smaller compared to the other direct wave, which is better transmitted in the basin. In the case of the distant source (aftershock No. 2), the direct S-wave is transmitted in the same way from both the lower boundary and the vertical edge of the basin. Consequently, the two phases arriving at the sediment sites have almost the same amplitude. The 




Fig. 5. Southern part of the velocity structure corresponding to line A-A'. This model, referred as Model-I in the text, shows the northern edge of the Osaka basin and array station locations. The other part of the model, not shown in the figure, is homogeneous with $V_{\mathrm{s}}=3.2 \mathrm{~km} / \mathrm{s}$.

kob25sh1.out

(a)



kob31sh1.out

(b)

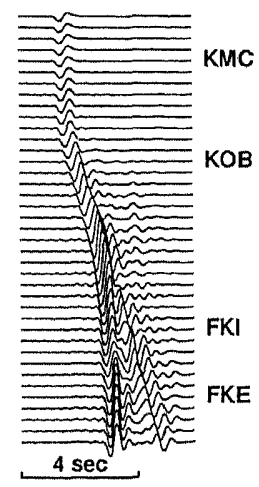

Fig. 6. Synthetic SH velocity seismograms calculated for receivers on free surface produced by Model-I, corresponding to aftershock No. 2 (a) and aftershock No. 4 (b). The distance between the receivers is $100 \mathrm{~m}$. The synthetic data corresponding to the array stations are indicated by the station name.

superposition between the two direct waves occurs at midway between FKI and KOB.

In Fig. 7(a) and (b), we compare the synthetic velocity with the tangential component of the velocity data. The synthetic seismograms and the data are band-pass filtered. As it can be seen in the figures, the waveforms are not well matched, especially at $\mathrm{KOB}$, which we consider as the key station for testing the accuracy of the assumed basin edge geometry. The synthetic waveforms at this station show only the direct wave arriving from the basin edge, while the records of both aftershocks show later phases having comparable amplitude with the first arrival. Moreover, on the synthetic seismograms of FKE, there are large later phases which do not exist in the records. These phases are produced by interference between the basinedge-transmitted-waves and the multiple reflected waves in the surface layers. Their amplitudes are controlled by the edge slope.

The comparison of synthetic and recorded waveforms of KOB suggests a more complex basin edge. Its effect should explain not only the waveform at $\mathrm{KOB}$ but also the small amplitude of the later phases observed at FKI and FKE.

It is apparent that the basin edge structure is not as simple as it is modeled. Basin-bounding faults covered by the quaternary basin sediments have been detected by recent seismic profiling (Committee of Earthquake Observation and Research in the Kansai Area (CEORKA), personal communications). They might have created a fault-like underground structure dipping to the north. Unfortunately, the seismic profiles do not pass through the Higashinada site 


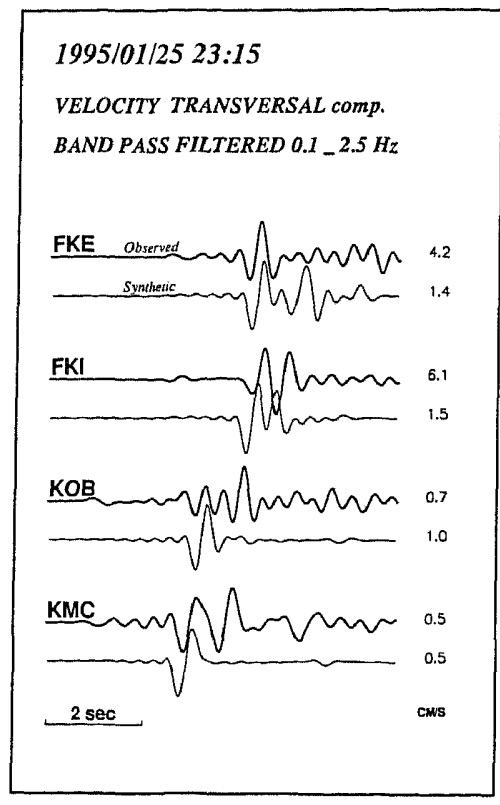

(a)

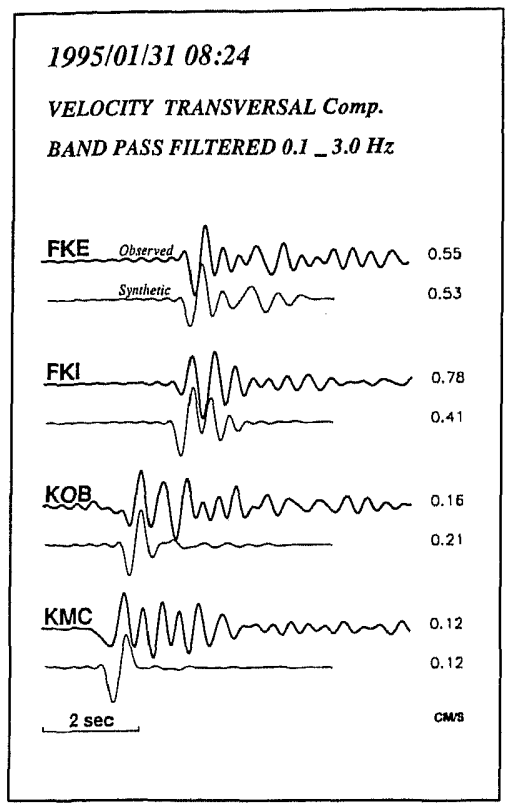

(b)

Fig. 7. (a) Comparison of the synthetic and observed tangential components of the velocity seismograms at KMC, KOB, FKI, and FKE for aftershock No. 2. The seismograms are produced by Model-I and band-pass filtered at $0.1-2.5 \mathrm{~Hz}$. (b) Comparison of the synthetic and observed tangential components of the velocity seismograms at KMC, KOB, FKI, and FKE for aftershock No.4. The seismograms are produced by Model-I and band-pass filtered at $0.1-3.0 \mathrm{~Hz}$.

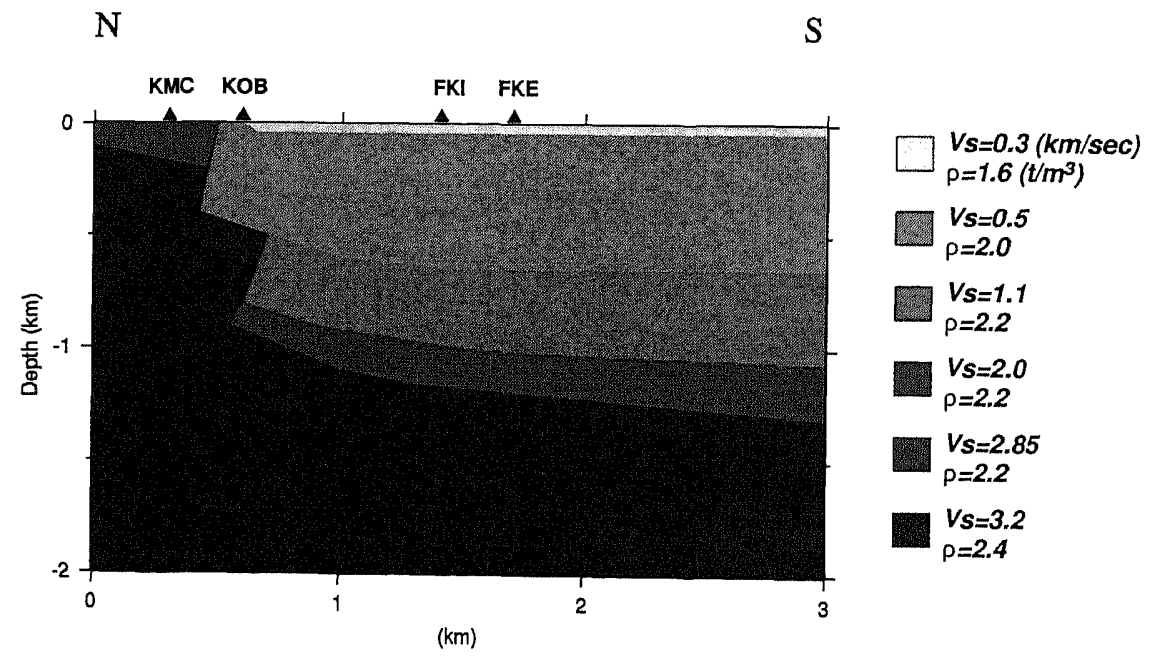

Fig. 8. Same as Fig. 5 but for the Model-II structure. 
(see Fig. 2).

In order to better satisfy the data, and based on the above-mentioned information, we propose the model shown in Fig. 8. Simulation results are shown in Fig. 9(a) and (b) for the aftershock Nos. 2 and 4 , respectively. The improvement in results is clearly seen in Fig. 10(a) and (b), which compare the synthetic waveforms with observed data. The

kob25sh4.out

(a)

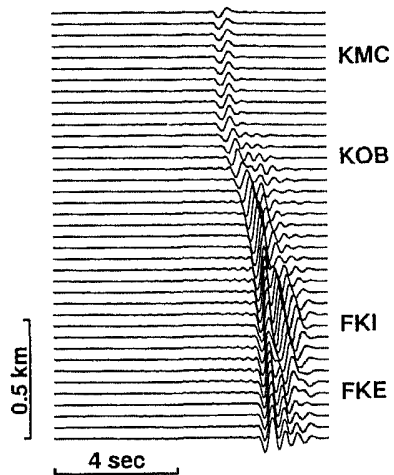

kob31sh4.out

(b)

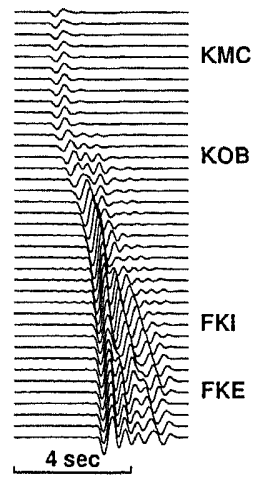

Fig. 9. Same as Fig. 6 but for the Model-II structure.

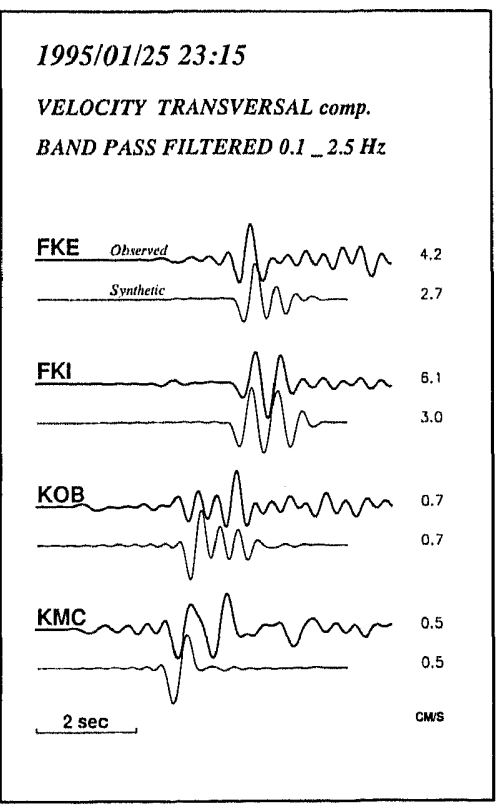

(a) synthetic waveforms for the near source (see Fig. 10(b)) match the data at the sediment sites very well, while for the distant source, the match at KOB is not very good (see Fig. 10(a)). The amplitude of the second phase observed at KOB is larger than the first phase. In the synthetic waveform, this situation is reversed. This might be because of the simplified basin edge model and the three-dimensional structure effects neglected in our simulations.

The amplitude of the later phases observed at $\mathrm{KOB}$ are much larger in the E-W component than in the N-S component (see Fig. 3). The amplitude in the transverse component, which has almost the same orientation as the $\mathrm{E}-\mathrm{W}$ component, is very sensitive to the aftershock location. Consequently, contamination of the observed transverse component from the radial component is also probable.

\section{Discussion and Conclusions}

The analysis of ground motions from aftershocks of the January 17, 1995 Hyogo-ken Nanbu earthquake, and the waveform modeling of two of the aftershocks show that the Osaka basin edge influenced the waveforms and the relative amplification at the sediment sites of the array observation. A summary of the simulated waveforms based on

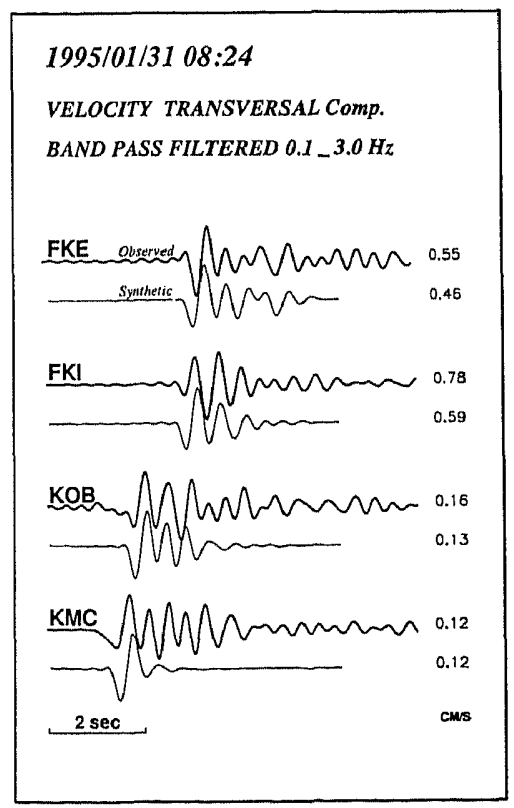

(b)

Fig. 10. Same as Fig. 7 but for the Model-II structure.

Vol. 44 , No. 5,1996 


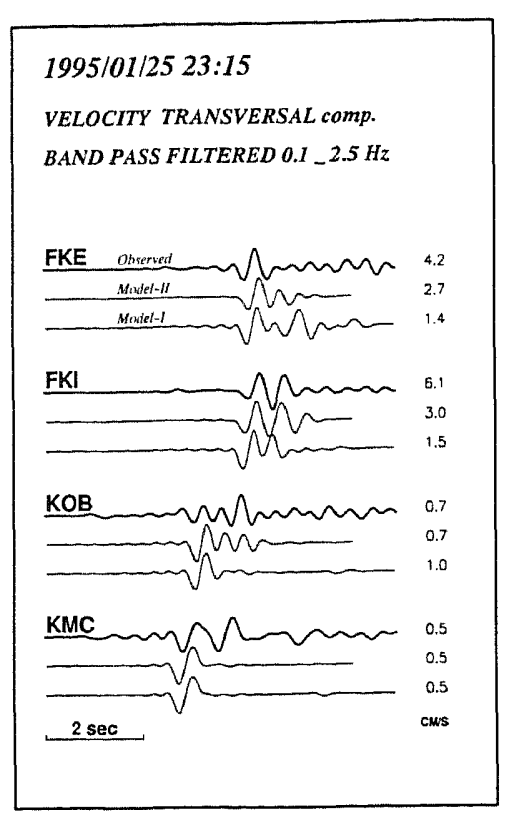

(a)

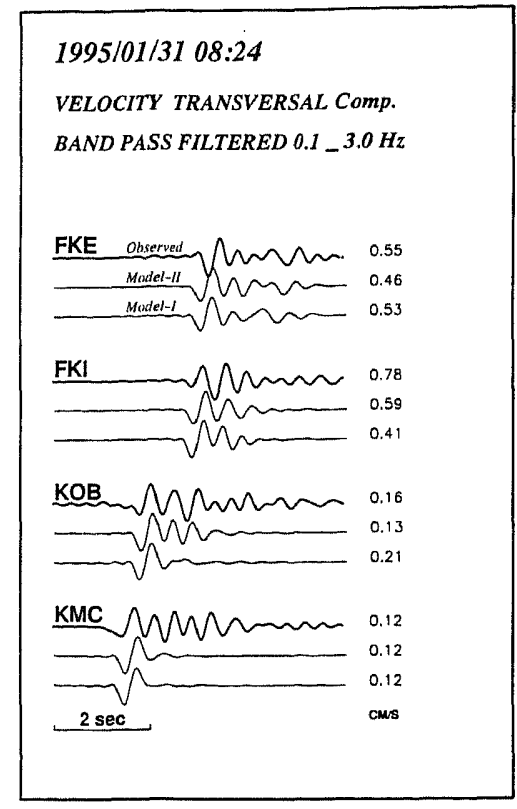

(b)

Fig. 11. (a) Comparison of the synthetic and observed tangential components of the velocity seismograms at KMC, KOB, FKI, and FKE for aftershock No.2, produced by Model-I and Model-II. The seismograms are band-pass filtered at $0.1-2.5 \mathrm{~Hz}$. (b) Comparison of the synthetic and observed tangential components of the velocity seismograms for KMC, KOB, FKI, and FKE for aftershock No. 4, produced by Model-I and Model-II. The seismograms are band-pass filtered at $0.1-3.0 \mathrm{~Hz}$.

\section{VELOCITY PEAK AMPLITUDE RATIOS} TRANSVERSE component
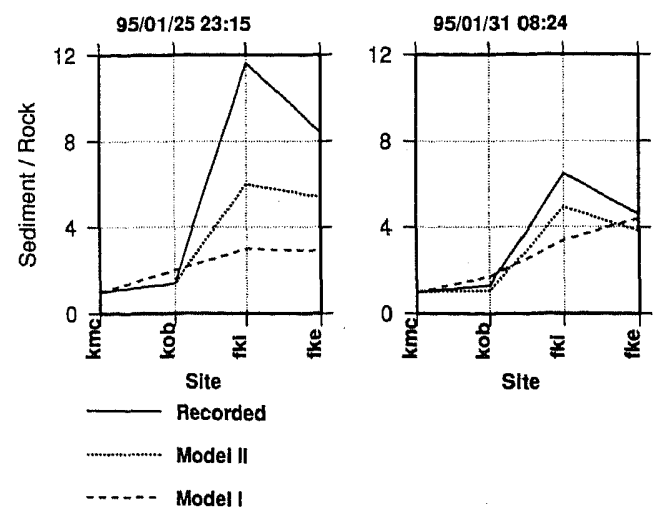

Fig. 12. Variation in the recorded and calculated peak amplitude ratio between the sediment sites and the rock site for aftershock No. 2 (left panel) and aftershock No. 4 (right panel). different basin edge structures is displayed in Fig. $11(a)$ and (b).

The preferred velocity model (Model-II) used in the final simulation could explain the variation in the peak amplitude ratios between sediment sites and the rock site for the closest source but not for the farthest one (Fig. 12).

The waveform modeling using a flat layered structure showed that the source radiation effect is not responsible for such discrepancy. One reason might be the fact that, depending on the source location, the ground motions at the rock site used as a reference are differently affected by the underground structure and the wave path. In our simulations, we utilized a rather homogeneous structure outside the basin.

It is interesting to see how the overall spectral content of the waveforms changed from station to station for both the observed and the synthetic data. The amplitudes of the Fourier transform of the transverse component records are compared with those of the synthetic data in Fig. 13(a) and (b) for 


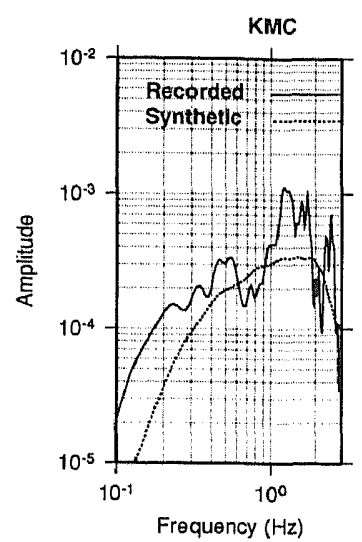

AMPLITUDE FOURIER SPECTRA Transversal Component Aftershock: 25/01/1995


(a)

AMPLITUDE FOURIER SPECTRA Transversal Component Aftershock: 31/01/1995
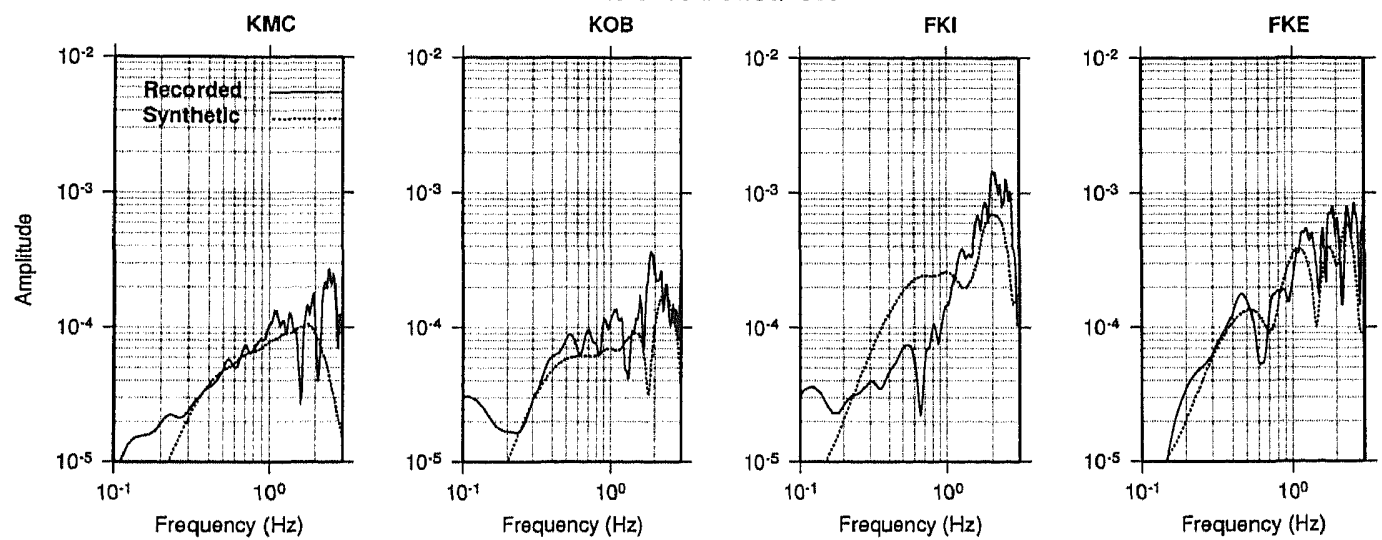

(b)

Fig. 13. (a) Comparison of the amplitude Fourier spectra of the recorded tangential components with those synthetically calculated for KMC, KOB, FKE, and FKI using Model-II, for aftershock No. 2. Before being Fourier transformed the seismograms were band-pass filtered from $0.1-2.5 \mathrm{~Hz}$. (b). Comparison of the amplitude Fourier spectra of the recorded tangential components with those synthetically calculated for KMC, KOB, FKE, and FKI using Model-II, for aftershock No. 4. Before being Fourier transformed the seismograms were band-pass filtered from $0.1-3.0 \mathrm{~Hz}$.

the aftershock Nos. 2 and 4, respectively.

By comparing the two figures, it is clear that the more distant aftershock has relatively large longperiod amplitude content (for frequencies smaller than $1.0 \mathrm{~Hz}$ ) which cannot be well modeled by the preferred velocity model and the adopted bellshaped source time function. The closest aftershock has a low content of long-period amplitude. In this case, the waves propagated through a very short path before entering in the basin; therefore, the wavepath effects are negligible. This is the reason why the velocity model does well in explaining the low-frequency amplitudes for the closest aftershock.

For both aftershocks, the amplitude Fourier spectra of the records at the soft sediment sites FKI and FKE show large amplifications at the predominant frequencies around $2 \mathrm{~Hz}$, while at $\mathrm{KMC}$ 
Table 3. One-dimensional structure models.

At KMC (rock site)

\begin{tabular}{lccc}
$\begin{array}{c}\text { Top depth } \\
(\mathrm{km})\end{array}$ & $\begin{array}{c}V_{\mathrm{S}} \\
(\mathrm{km} / \mathrm{s})\end{array}$ & $\begin{array}{c}\text { Density } \\
\left(\mathrm{t} / \mathrm{m}^{3}\right)\end{array}$ & $Q_{\mathrm{S}}$ \\
\hline 0.0 & 1.3 & 2.2 & 150 \\
0.03 & 1.8 & 2.4 & 200 \\
0.1 & 3.2 & 2.5 & 300 \\
\hline
\end{tabular}

At FKE (soil site)

\begin{tabular}{llll}
\hline $\begin{array}{c}\text { Top depth } \\
(\mathrm{km})\end{array}$ & $\begin{array}{c}V_{\mathrm{s}} \\
(\mathrm{km} / \mathrm{s})\end{array}$ & $\begin{array}{c}\text { Density } \\
\left(\mathrm{t} / \mathrm{m}^{3}\right)\end{array}$ & $Q_{\mathrm{S}}$ \\
\hline 0.0 & 0.1 & 1.4 & 30 \\
0.007 & 0.2 & 1.6 & 50 \\
0.02 & 0.4 & 1.8 & 80 \\
0.075 & 0.6 & 2.2 & 100 \\
0.5 & 1.2 & 2.2 & 150 \\
0.9 & 2.85 & 2.3 & 220 \\
1.0 & 3.2 & 2.5 & 300 \\
\hline
\end{tabular}

their spectral amplitudes are different at those frequencies. This might be another reason why the peak amplitude ratio of the soft sediments verses rock site is different for the two aftershocks.

By comparing their frequency contents from $1.0-2.5 \mathrm{~Hz}$, we can conclude that the relative spectral amplification from site to site is very similar for the two aftershocks.

While there is a rather good match in the spectral shape and in its relative variation from station to station, the spectral amplitudes of the records are larger than those of the synthetic seismograms for both aftershocks in the frequency range $1.0-2.5 \mathrm{~Hz}$. This is probably due to the influence of thin surface layers, with lower S-wave velocities, on the observed ground motions. The thin surface layers are not included in the velocity model used in the simulations. Their inclusion would make the calculation difficult to perform because finitedifference calculations in a very fine grid would be required. By waveform simulations using a horizontally stratified medium, Iwata et al. (1995) found that existing low-velocity surface layers (less than $10 \mathrm{~m}$ ) amplified the displacement of the ground motions at FKI.

In order to evaluate the influence of basin sedimentary-layers on ground motions, we calcu-

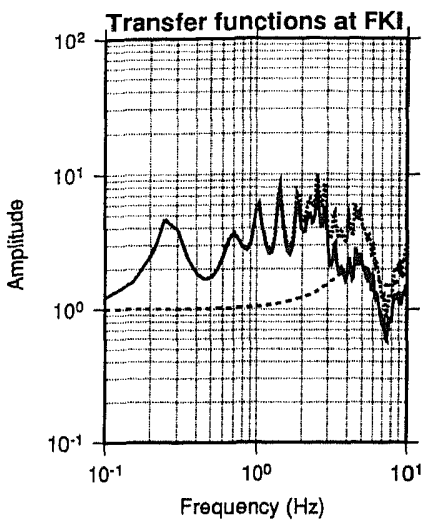

Fig. 14. Transfer functions at KMC (dotted line) and FKI (broken line), calculated for the one-dimensional velocity models shown in Table 3 , and their spectral ratio (solid line).

lated the transfer function at the rock site and at one sediment sites (FKI) using one-dimensional velocity models (see Table 3) and the vertical incidence of planar S-waves. The one-dimensional model used in the calculations for KMC corresponds to the velocity structure beneath $\mathrm{KMC}$ derived from Model-II, while for FKI, we utilized the onedimensional structure proposed by Iwata et al. (1995) (Model C in their paper). The transfer functions calculated using the propagator-matrix technique (Haskell, 1953) and their spectral ratio are shown in Fig. 14.

At the rock site, the transfer function is flat in the frequency range of $0.1-3 \mathrm{~Hz}$, while at the sediment site, the transfer function has several peaks corresponding to different resonant modes. The peak observed at $0.25 \mathrm{~Hz}$ is due to the influence of deep sedimentary layers. The very soft sediment surface layers amplify at frequencies higher than $1.0 \mathrm{~Hz}$.

The obtained spectral amplification due to the one-dimensional structure is insufficient to explain the observed velocity amplification at FKI in the frequency range of $1.0-3.0 \mathrm{~Hz}$. A combination of the two-dimensional basin effects, considerable at $1.0-2.5 \mathrm{~Hz}$, and the thin low-velocity layers effect can fully explain the observed ground motions.

Our simulation shows that the two-dimensional basin edge geometry along a profile perpendicular to the basin can be responsible for the variation in ground motion recorded at receivers close to the basin edge. Independent of the small complexities of the basin edge, it can focus the seismic energy at 


\section{VELOCITY PEAK AMPLITUDE RATIO}

Model-Ill

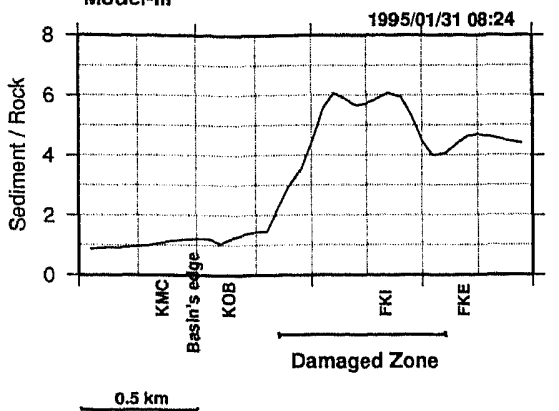

Fig. 15. Peak amplitude variation derived from the synthetic SH velocity seismograms produced by Model-II, for aftershock No. 4. All the synthetic data were first band-pass filtered from 0.1 $3.0 \mathrm{~Hz}$, and then normalized by the peak amplitude of the synthetic velocity corresponding to the first receiver. The relative location of the array stations and the corresponding section of the damaged zone along the $\mathrm{N}-\mathrm{S}$ direction are also indicated.

particular points where the superposition of different basin-generated waves might strongly amplify the ground motion. However, our results indicate that a basin structure lacking extremely low velocity layers near the surface cannot model the observed large amplification in the frequency range of $1.0-2.5 \mathrm{~Hz}$.

The synthetic waveforms calculated at receivers crossing to the basin edge, using the preferred model for the basin structure, indicate that the amplification due to the basin edge effects is relatively large in a narrow range, as shown in Fig. 15. This range is broadened if we consider a more complex stair-step-like basin edge structure. The attenuation, not taken into consideration here, might decrease the overall amplification and change the width of the maximum amplification zone.

Amplification depends not only on the basin edge geometry but also on the source location. As a result, during the main shock, which had a complex source process dominated by at least three subevents (Wald, 1995; Yoshida et al., 1996), the amplification due to the basin edge effect might have been even stronger in particular zones, depending on the location of the asperities on the fault. Our simulation indicates that the very local amplification due to the basin edge effects might have been one of the reasons why the heavily damaged zone lies along a narrow belt. It also indicates that the seismic energy focussing is not significantly different if the seismic event is located a few kilometers from the basin or immediately adjacent to it.

Our two-dimensional wave propagation modeling is a preliminary effort in the construction of a three-dimensional model of the basin structure in Kobe area. It can be considered as additional information beyond the geophysical and geological data.

We thank Hiroo Nemoto for relocating and calculating the focal mechanism of the aftershocks modeled in our study. The paper benefits from the critical review of two anonymous reviewers. This study was supported in part by a Grant-in-Aid for Scientific Research (No. 06650630) from the Ministry of Education, Science, Sports and Culture, Japan.

\section{REFERENCES}

Aki, K., Local site effects on ground motion, in Earthquake Engineering and Soil Dynamics II-Recent Advances in Ground Motion Evaluation, Geotechnical Special Publication No. 20, ed. J. L. Von Thun, pp. 103-155, American Society of Civil Engineers, New York, 1988.

Boore, D. M., Finite-difference methods for seismic wave propagation in heterogeneous materials, in Methods in Computational Physics, ed. B. A. Bolt, Academic Press, New York, Vol. 11, 1972.

Frankel, A., Three-dimensional simulations of ground motions in the San Bernardino valley, California, for hypothetical earthquakes on the San Andreas fault, Bull. Seismol. Soc. Am., 83, 1020-1041, 1993.

Gao, S., H. Liu, P. M. Davis, and L. Knopoff, Localized amplification of seismic waves and correlation with damage due to the Northridge earthquake: Evidence for focusing in Santa Monica, Bull. Seismol. Soc. Am., 86B, S209-S230, 1996.

Graves, R. W., Preliminary analysis of long-period basin response in the Los Angeles region from the 1994 Northridge earthquake, Geophys. Res. Lett., 20 , 101-104, 1995.

Haskell, N. A., The dispersion of surface waves in multi-layered media, Bull. Scismol. Soc. Am., 43, 17-43, 1953.

Hauksson, E., Earthquakes, faulting and stress in the Los Angeles basin, J. Geophys. Res., 95, 15365-15394, 1990.

Heimberger, D. V. and J, E. Vidale, Modeling strong motions produced by earthquakes with two-dimensional numerical codes, Bull. Seismol. Soc. Am., 78, 109-121, 1988. 
Huzita, K. and T. Kasama, Geology of the OsakaSeihokubu District. Quadrange series, scale 1:50.000, Kyoto 11 (50), Geol. Surv., Jpn., 112 pp, 1982 (in Japanese with English abstract).

Iwata, T., K. Hatayama, H. Kawase, K. Irikura, and K. Matsunami, Array observation of aftershocks of the 1995 Hyogoken-nanbu earthquake at Higashinada Ward. Kobe city, J. Nat. Disas. Sci., 16, 41-48, 1995.

Kagawa, T., S. Sawada, Y. Iwasaki, and A. Nanjo, On the modelization of deep sedimentary basin structure beneath the Osaka plain, Abstr., Seismol. Soc. Jpn., 2, 112-117, 1993 (in Japanese).

Kamae, K. and K. Irikura, A fault rupture model of the 1995 Hyogoken-nanbu earthquake $\left(M_{\mathrm{JMA}}=7.2\right)$ estimated by empirical Green's function method, J. Nat. Disas. Sci., 16, 31-40, 1995.

Kawase, H. and Y. Hayashi, Strong motion simulation in Chuo, Kobe, during the Hyogoken-nanbu Earthquake of 1995 based on the inverted bedrock motion, J. Struct. Construct. Eng. (Trans. AIJ), 480, 67-76, 1996.

Kudo K., M. Takahashi, M. Sakaue, S. Suzuki, and R. Inoue, Effects of surface geology on strong motion during the Hyogo-ken Nanbu Earthquake-Aftershock observation and detailed survey on structure damage in West Kobe--, Programme and Abstracts, Seismological Society of Japan, 2, A99, 1995 (in Japanese).

Motosaka, M. and M. Nagano, Analytical study on ground motion amplification characteristics in Kobe City during the 1995 Hyogo-ken Nanbu Earthquake taking into account of irregular underground structure, Programme and Abstracts, Seismological Society of Japan, 2, A101, 1995 (in Japanese).

Pitarka, A. and K. Irikura, Basin structure effects on long period strong motions in the San Fernando valley and in the Los Angeles basin from the 1994 Northridge earthquake and an aftershock, Bull. Seismol. Soc. Am.,
86, S126-S137, 1996.

Pitarka, A., K. Irikura, and T. Kagawa, Source complexity of the January 17, 1995 Hyogoken-nanbu earthquake from nearfield strong motion modeling. Preliminary results, J. Nat. Disas. Sci., 16, 31-37, 1995.

Scrivner, C. W. and D. V. Helmberger, Seismic waveform modeling in the Los Angeles basin, Bull. Seismol. Soc. Am., 84, 1310-1326, 1994.

Sekiguchi, H., K. Irikura, T. Iwata, Y. Kakehi, and M. Hoshiba, Minute locating of faulting beneath Kobe and the waveform inversion of the source process during the 1995 Hyogo-ken Nanbu, Japan, earthquake using strong ground motion records, J. Phys. Eurth, 44, 473-487, 1996.

Shinozaki, Y. and K. Yoshida, Seismic waves in 3-D sedimentary basins due to point source (2), Programme and Abstracts, Seismological Society of Japan, 2, A100, 1995 (in Japanese).

Tessmer, E. and D. Kosloff, 3-D elastic modeling with surface topography by a Chebychev spectral method, Geophysics, 59, 464-473, 1994.

Toki, K., K. Irikura, and T. Kagawa, Strong motion data recorded in the source area of the 1995 Hyogoken-nanbu earthquake, January 17, 1995 Japan, J. Nat. Disas. Sci., 16, 23-30, 1995.

Vidale, J. E., D. H. Helmberger, and R. W. Clayton, Finite-difference seismograms for $\mathrm{SH}$ waves, Bull. Seismol. Soc. Am., 75, 1765-1782, 1985.

Wald, D. J., 1995, A preliminary dislocation model for the 1995 Kobe (Hyogo-ken Nanbu), Japan, earthquake determined from strong motion and teleseismic waveforms, Seismol, Res, Lett., 66, 22-28.

Yoshida, S., K. Koketsu, B. Shibazaki, T. Sagiya, T. Kato, and $Y$. Yoshida, Joint inversion of near- and far-field waveforms and geodetic data for the rupture process of the 1995 Kobe earthquake, J. Phys. Earth, 44, 437-454, 1996. 